Produção na Escrita de Histórias

\title{
A Influência de Diferentes Situações de Produção na Escrita de Histórias
}

\author{
Maria Emilia Lins e Silva \\ Alina Galvão Spinillo ${ }^{12}$ \\ Universidade Federal de Pernambuco
}

\begin{abstract}
Resumo
O estudo examinou o efeito de diferentes situações de produção na escrita de histórias. Oitenta crianças de primeira à quarta série do ensino fundamental escreveram histórias em quatro situações distintas: produção livre; produção oral/escrita; produção a partir de sequêencia de gravuras; e reprodução de uma história ouvida. Inicialmente, 320 histórias foram classificadas em categorias hierárquicas de organização textual. Em um segundo momento, cada criança foi analisada ao longo das quatro condições. As condições experimentais tiveram um efeito sobre qualidade narrativa das histórias: as mais elaboradas eram aquelas produzidas a partir da sequêencia de gravuras e a partir da história ouvida. Este efeito não foi observado entre as crianças das séries mais adiantadas, cujas histórias apresentavam uma estrutura narrativa elaborada em todas as condições. Identificouse três níveis de desenvolvimento quanto à habilidade narrativa na escrita de histórias, desenvolvimento este que ocorre mesmo após a instrução formal da leitura e da escrita.

Palavras-chave: Situações experimentais; história escrita; desenvolvimento de habilidades narrativas.
\end{abstract}

The Effect of Different Situations on Written Stories

Abstract

This study investigates the effect of experimental situations on written stories. Eighty first to fourth graders were asked to write stories under four different situations: free story production, oral/written story production from a sequence of pictures, and reproduction of a story read to the child. The 320 collected stories were hierarchically classified according to their textual organization. Also, each child had her/his performance analyzed across situations. The conditions had an effect on the stories produced: stories with a high level of narrative schema were those produced from both a sequence of pictures and a story read to the child. This effect was not observed among the third and fourth graders whose stories were of a higher level of narrative structure in all conditions. Each child was assigned to one of the three levels of narrative competence. Thus, the domain of narrative structure develops even after the formal instruction on reading and writing.

Keywords: Experimental situations; written stories; narrative development.

"A palavra texto expressa o papel central da escrita no processo de letramento. Texto é fazer da linguagem um objeto reproduzivel e visivel que pode ser repetido, citado, e relatado. Texto é a mensagem escrita materializada em um artefato (e.g.; um livro ou uma carta, mas também em uma camiseta ou em embalagens de alimentos) que provê um contexto para a interpretação dos sinais escritos. Aprender a produzir e a compreender textos significa tornar-se letrado." (Pontecorvo, Orsolini \& Resnick, 1996, p. ix)

Duas principais áreas de interesse caracterizam os estudos sobre a escrita. Como mencionado por

1 Endereço para correspondência: Universidade Federal de Pernambuco, Pós-Graduação em Psicologia - CFCH 80. andar, Cidade Universitária, 50.670-901 Recife, PE. Fax: (81) 271-1843, Fone: (81) 271-0599 e 271-8272, Email:spin@npd.ufpe.br

${ }^{2} \mathrm{O}$ artigo faz parte da Dissertação de Mestrado da primeira autora, sob a orientação da segunda, na Pós-Graduação em Psicologia da UFPE. As autoras agradecem o apoio da CAPES e FACEPE sob forma de bolsa de estudos conferida à primeira autora. Agradecimentos são endereçados à Lúcia Lins Browne Rego pelos comentários e sugestões, sempre pertinentes, relativos a este estudo, em sua fase inicial.
Pontecorvo (1997) e Pontecorvo e Orsolini (1996), a escrita pode ser tratada como o processo de traçar símbolos sobre o papel; e como o processo de produção de textos ${ }^{3}$. A primeira focaliza os diferentes sistemas de escrita, sua natureza, os aspectos notacionais, o desenvolvimento na aquisição de um dado sistema (o alfabético, por exemplo), tratando, ainda, das relações entre a linguagem oral e a escrita. A segunda área relaciona-se à escrita de unidades lingüísticas maiores do que palavras e frases, focalizando o discurso, o texto e seus gêneros. Embora distintos, o uso de um sistema de representação e a produção de linguagem escrita fazem parte da aquisição e desenvolvimento da escrita de modo ${ }^{3}$ Pontecorvo (1997) denomina a primeira perspectiva como systems of
writing/writing of language, e a segunda como written language. Esta
terminologia equivale à distinção feita nos Parâmetros Curriculares
Nacionais - Língua Portuguesa (1997) sobre a escrita da linguagem e a linguagem escrita, respectivamente. 
geral, estando ambos contemplados em teorias sobre letramento (e.g., Castell, Luke \& McLennan, 1986; Olson, 1997) e em propostas educacionais (ver Parâmetros Curriculares Nacionais Língua Portuguesa, 1997). A separação destes aspectos decorre da necessidade de investigar-se cada um deles isoladamente.

A presente investigação versa sobre o segundo enfoque, tratando da produção escrita de histórias por crianças, examinando o desenvolvimento da aquisição da estrutura narrativa em histórias escritas. Dois fatores são considerados:

- o efeito das séries subseqüientes à alfabetização: Os anos escolares após a alfabetização influenciam a qualidade narrativa das produções escritas? É possível supor que crianças já alfabetizadas que dominam a escrita da linguagem produziriam histórias com uma estrutura narrativa elaborada, e que a escolaridade após a alfabetização teria um efeito pouco expressivo sobre as produções escritas. Outra possibilidade é que, mesmo após a alfabetização, haveria uma evolução quanto à escrita de histórias, evolução esta que não seria 'nivelada' pela aquisição formal da leitura e da escrita.

- o efeito das condições de produção: A condição em que criança é solicitada a escrever influencia a qualidade narrativa da história, como ocorre com a produção oral? Considerando que o texto escrito é mais descontextualizado e autônomo que o texto oral (pelo menos em certo sentido), é possível supor que escrita seria pouco susceptível a variações experimentais, e que histórias escritas apresentariam níveis semelhantes quanto à estrutura narrativa, independentemente das condições de produção.

O Desenvolvimento de um Esquema Narrativo de Histórias

Produzir uma história, seja ela oral ou escrita, é uma atividade cognitiva e lingüística. Dentre os inúmeros conhecimentos lingüísticos envolvidos, o conhecimento sobre as convenções e sobre a estrutura de história têm sido amplamente examinados em uma perspectiva de desenvolvimento, em particular em relação à produção oral de histórias.

\section{Produção Oral}

Produzir histórias não é tarefa fácil para crianças pré-escolares, como afirma Dowker (1986), ao comentar que são raras as produções que, nesta faixa etária, incluem um enredo com a introdução de uma situação-problema e um desfecho. A habilidade de contar histórias é gradativamente adquirida mesmo durante os anos escolares (e.g., Pontecorvo \& Zucchermaglio, 1989; Stein, 1988).

Um exemplo desta evolução é documentado por Hudson e Shapiro (1991) ao comparar crianças pré-escolares e de séries iniciais do ensino elementar (quatro, seis e oito anos) quanto à produção oral de scripts, histórias e relatos de experiência pessoal sobre tópicos diversos. As autoras tinham por objetivo investigar o desenvolvimento de habilidades narrativas gerais comuns aos tipos de textos examinados, e de habilidades específicas, particulares a cada tipo. Destacando-se os resultados obtidos em relação apenas à produção oral, verificou-se que, com o aumento da idade/escolaridade, as histórias tornavam-se mais complexas e elaboradas. Enquanto as crianças pré-escolares incluíam poucos componentes próprios de história em suas narrativas, as crianças da primeira série incluíam mais freqüentemente situações-problema e o final. Mais da metade das produções da terceira série apresentava uma introdução, situação-problema, resolução e um final conectado de forma clara com a situação-problema; o que não era observado nas produções da primeira série. Assim, histórias completas e elaboradas são mais freqüentes entre as crianças de terceira série.

Berman e Slobin (1994) desenvolveram um extenso estudo comparativo entre cinco diferentes línguas (inglês, alemão, espanhol, hebraico e turco) com crianças de três, quatro, cinco e nove anos, e adultos. A partir de uma seqüencia de gravuras apresentada em formato de livro, solicitava-se a produção oral de uma história. Após folhear o livro como um todo, os participantes contavam a história enquanto olhavam as gravuras. Três componentes foram considerados na análise das produções: Componente I - início do problema que mostrava as ações do personagem; Componente II - as tentativas de resolução conduzidas pelo personagem; e Componente III - a resolução do problema. Estes componentes correspondem, de forma global, aos componentes especificados pelas gramáticas de história. A presença desses componentes nas narrativas variava entre as idades: as crianças de cinco anos mencionavam mais freqüentemente o Componente $\mathrm{I}$, as de nove anos o Componente II e os adultos o Componente III. O número de participantes que expressavam uma estrutura narrativa elaborada, fazendo referência aos três componentes em um mesma história, também variava entre as idades: $3 \%$ das crianças de três anos; $14 \%$ das de quatro anos; $34 \%$ das crianças de cinco anos; $66 \%$ das crianças de nove anos e $92 \%$ dos adultos. Verificou-se, ainda, que as crianças mais novas apoiavam-se mais em referenciais extralingüísticos (pistas contextuais) do que 
as crianças de cinco anos que já contavam uma história com base em referenciais intralingüísticos. Crianças em idade escolar usavam a linguagem para organizar suas narrativas de forma mais elaborada e alcançavam alto nível de coerência, mostrando familiaridade com as normas de contar histórias próprias de sua cultura, produzindo cadeias narrativas mais organizadas. Apenas os adultos mostraram uma maior flexibilidade lingüística e uso de expressões diversas em suas produções. Observou-se uma grande consistência entre as línguas a partir dos cinco anos, ocorrendo maior variabilidade entre as crianças de três e quatro anos. Concluiu-se que há padrões similares de desenvolvimento em relação às idades e às diferentes línguas quanto à produção de uma narrativa elaborada.

Além da idade, a escolaridade aparece como fator importante neste desenvolvimento, como mostram as pesquisas de Spinillo (1993) com crianças brasileiras, e de Spinillo e Pinto (1994) com crianças inglesas e italianas. Nestes estudos, crianças de mesma idade, porém em séries distintas, se diferenciavam quanto à qualidade narrativa de suas histórias: as melhores produções eram encontradas entre as crianças alfabetizadas. Resultado semelhante foi verificado por Spinillo e Martins (1997) ao investigarem a produção de histórias coerentes, em que o fato de estar alfabetizado era mais determinante do nível de coerência do que a idade apenas.

Evidencia-se, portanto, que na produção oral existe uma evolução quanto ao domínio das convenções e da estrutura próprias da história. Esta evolução depende tanto da idade como da escolaridade. Seria uma evolução semelhante encontrada na produção escrita de histórias?

\section{Produção Escrita}

A escrita de histórias é menos investigada que a produção oral. Muitos dos estudos sobre a escrita de histórias adotam um enfoque essencialmente pedagógico voltado para propostas de atividades em sala de aula, sendo negligenciados os aspectos psicolingüísticos envolvidos neste processo. Entretanto, é possível encontrar na literatura alguns estudos que focalizam a produção escrita em uma perspectiva de desenvolvimento.

Rego (1985), em um estudo de caso, investigou a aquisição da linguagem escrita de sua filha Fabiana entre os quatro e sete anos de idade que esteve exposta a momentos intensos de leitura e escrita de histórias no contexto familiar, antes e durante o ingresso na alfabetização. As histórias escritas de Fabiana desde cedo já evidenciavam a capacidade de produzir narrativas compatíveis com o estilo formal da língua escrita. Esta preparação informal permitiu o desenvolvimento do Psicologia: Reflexão e Crítica, 2000, 13(3), pp.337-350 conhecimento da linguagem escrita relevante para à aquisição posterior da leitura e da escrita no contexto escolar.

Em outro estudo, Rego (1986) analisou histórias escritas por crianças de primeira série de escola particular, com o objetivo de investigar os diferentes níveis de conhecimento que apresentavam em relação à estrutura básica de histórias. Cerca de 47\% dos textos produzidos eram não-histórias (textos sem as características convencionais deste tipo de registro), e que pouco mais da metade dos textos $(53 \%)$ apresentavam marcadores lingüísticos convencionais e alguns princípios de coesão textual. Apenas 3\% das produções eram histórias completas que seguiam os padrões convencionais e a estrutura desse gênero narrativo. Importante mencionar que apesar das crianças serem de mesma idade e da mesma série, existiam diferentes níveis de domínio de um esquema narrativo entre elas. Isto mostra que este domínio não depende apenas de fatores como idade e série, estando envolvidos outros aspectos nesta aquisição, como a exposição e contato que estas crianças tiveram no contexto familiar.

O efeito da escolaridade sobre a escrita de histórias foi explorado por Buarque, Higino, Miranda, Dubeux e Pedrosa (1992) com crianças de baixa renda alunas da primeira à quarta série de escolas públicas em Pernambuco. Observou-se que os percentuais de não-histórias (bilhetes, cartas, textos cartilhados etc.) diminuíam com o aumento em escolaridade; enquanto aumentava o percentual de histórias completas e bem elaboradas. Nota-se, portanto, uma progressão na escrita de histórias com o aumento da escolaridade, tanto em relação à produção de um texto considerado como história quanto à produção de uma história completa.

Teberosky (1995) investigou a reescrita de vários gêneros de textos (história, notícias jornalísticas e descrição) em crianças de seis a dez anos de idade no contexto de sala de aula. A autora comparou os textos originais apresentados (texto-modelo) com os textos reescritos pelas crianças, verificando similaridades entre o texto-modelo e o texto reescrito quanto: (a) à fidelidade ao tópico; (b) às características sintáticas de modo, tempo e pessoa, e (c) à adequação ao gênero ao qual o textomodelo pertencia. De modo geral, os resultados mostraram que ao reproduzir por escrito um texto escrito (reescrita de textos) a criança imita as características deste texto, características estas que não se restringem apenas ao conteúdo do texto original, mas às suas características lingüísticas e estruturais. Será que as crianças reproduziriam tais características do texto-modelo caso a situação envolvesse a reprodução escrita de um texto oral? 
Lins e Silva e Spinillo (1998) compararam a escrita de histórias em crianças de classes sociais distintas (classe média e baixa renda), porém já alfabetizadas e com os mesmos anos de escolaridade e de exposição à linguagem escrita no contexto escolar. Cada criança era solicitada a escrever uma história sobre o tema que desejasse, sendo, então, as produções classificadas em função do nível de esquema narrativo que apresentavam. Em ambos os grupos, logo após a alfabetização, é pouco freqüente escrita de histórias bem elaboradas; o que só ocorria passados alguns anos de escolaridade após a alfabetização A principal diferença entre os grupos residia no fato de que o progresso na escrita de história era mais marcante entre as crianças de classe média do que entre as de baixa renda. Este resultado foi discutido em função de fatores sóciolingǘsticos relativos a diferenças quanto às experiências, oportunidades, contatos e interações que crianças de classes sociais distintas têm em relação à linguagem dos textos no ambiente familiar.

O que se pode concluir a partir desses estudos, é que, semelhante ao que ocorre com a produção oral, há uma progressão na escrita de histórias. Esta progressão esta relacionada não apenas à idade e escolaridade, mas também ao contato que a criança tem com textos no ambiente familiar, contato este que varia entre classes sociais distintas. Nota-se, ainda, que além da produção livre, a reprodução escrita de textos é aspecto importante que merece ser investigado, tanto entre diferentes gêneros de textos como entre crianças com idade/escolaridade diferentes.

O Efeito de Variações Experimentais na Produção

\section{de Histórias}

Outro aspecto relevante sobre o tema refere-se ao efeito da situação de produção sobre a qualidade narrativa da história. Analisando-se as inúmeras situações de produção propostas às crianças nas pesquisas na área, nota-se que há uma enorme variabilidade entre estas situações: histórias produzidas a partir de gravuras (uma única gravura ou uma seqüência delas), a partir de desenho feito pela própria criança, a partir de filmes, da apresentação de um tema ou fornecimento de um título, etc. O efeito dessas variações tem sido analisado em relação à produção oral, porém, este aspecto não tem sido examinado em relação à escrita de histórias, como pode ser constatado nos estudos apresentados a seguir.

Produção Oral

Estudos mostraram que as histórias orais produzidas por uma mesma criança variam de uma situação a outra quanto ao nível da estrutura narrativa que apresentam.
O uso de expressões referenciais por crianças de 4 anos foi investigado por Orsolini e Di Giacinto (1996) que compararam duas situações de produção. $\mathrm{Na}$ primeira, as crianças inventavam histórias e as dramatizavam através de brinquedos. Na segunda situação, a criança reproduzia uma história ouvida. Os resultados mostraram que introduzir um novo personagem através de expressões referenciais indefinidas (nome ou artigo indefinido) era mais freqüente na reprodução do que na produção espontânea. A comparação entre histórias inventadas e histórias reproduzidas sugere que a seleção feita pela criança de formas indefinidas não decorre da necessidade de querer assinalar para o ouvinte que a informação introduzida no discurso é nova, mas deriva-se da reprodução das convenções textuais apresentadas. $\mathrm{Na}$ realidade, as crianças produzem as expressões indefinidas e convenções textuais apenas quando reproduzem. A situação de reprodução, portanto, favorece o uso de referenciais indefinidos, que são mais apropriados ao texto, do que quando na produção livre.

Outros estudos compararam, em um mesmo grupo de crianças, o efeito do apoio visual na produção oral de histórias. Spinillo (1991) analisou as histórias produzidas por crianças de quatro a oito anos em duas condições: uma com e outra sem o apoio de recurso visual (desenho feito pela criança). As histórias produzidas a partir do desenho foram classificadas em níveis mais elementares do que aquelas produzidas sem o apoio visual, apresentando características da linguagem oral, caracterizando-se como meras descrições do desenho feito, sendo, ainda, dependentes do apoio visual e de referenciais extralingüísticos. $\mathrm{Na}$ ausência deste apoio, as histórias eram mais elaboradas, apresentando organização e convenções lingüísticas próprias do estilo narrativo literário. Concluiu-se que, nesta faixa etária, o recurso visual desempenha um papel restritivo quanto à qualidade das narrativas.

Em estudos subseqüentes, o efeito das variações experimentais sobre a produção de histórias orais foi mais detalhadamente examinado (Spinillo, 1993; Spinillo \& Pinto, 1994). Spinillo e Pinto (1994) investigaram crianças inglesas e italianas (quatro, seis e oito anos), onde cada criança era solicitada a contar uma história em quatro situações distintas: produção com o apoio de gravuras (desenho feito pela criança e seqüência de gravuras), e produção livre (história apenas, e criar/ditar uma história para o experimentador). Com base no estudo anterior (Spinillo, 1991), as autoras levantaram a hipótese de que variações experimentais provocariam diferentes níveis de desempenho: as histórias mais elaboradas seriam aquelas produzidas na ausência de recursos visuais; e que as 
histórias produzidas a partir da seqüência de gravuras seriam mais sofisticadas do que a partir do desenho, uma vez que a seqüência de gravuras sugeria elementos importantes da história (tema, cena, protagonistas, ações). Ao contrário do esperado, não detectou-se diferenças significativas entre as situações com apoio visual (desenho vs. gravuras), sendo as diferenças detectadas apenas em função da presença ou ausência do estímulo visual. Histórias produzidas sem a utilização de gravuras/ desenho eram mais elaboradas do que aquelas produzidas a partir deste recurso. Este resultado confirma o dados obtidos no estudo anterior (Spinillo, 1991).

Resultado diferente foi encontrado por Cain (1996) e Cain e Oakhill (1996) quanto ao papel desempenhado pelo apoio visual na produção oral. As autoras investigaram as relações entre o conhecimento de histórias e habilidade de compreensão, sendo o conhecimento de histórias avaliado em função da habilidade de contar histórias. Duas situações de produção foram contrastadas: contar uma história a partir de uma seqüência de gravuras, e a partir de um título fornecido pelo examinador. Crianças de sete-oito anos foram divididas em grupos em função da idade, da capacidade de compreensão e precisão de leitura. Com o apoio das gravuras, as histórias eram melhor estruturadas e completas do que quando produzidas a partir do título. Isto era mais marcante entre as crianças com dificuldades de compreensão para as quais o apoio fornecido pela seqüência de gravuras auxiliava na produção de histórias mais estruturadas.

O efeito de apoios visuais sobre a produção oral de histórias foi mais sistematicamente examinado e esclarecido no estudo desenvolvido por Shapiro e Hudson (1997). Crianças (quatro e seis anos) foram solicitadas a contar histórias a partir de dois tipos de sequêencia de gravuras apresentadas em formato de livro. Uma seqüência consistia em gravuras que representavam eventos que se seguiam cronologicamente (semelhantes ao estímulo visual adotado por Spinillo); e a outra seqüência envolvia uma situação-problema (semelhante ao estímulo visual adotado por Cain, 1986). Os resultados revelaram que as histórias produzidas a partir de seqüência de gravuras com uma situação-problema eram mais elaboradas do que aquelas produzidas a partir da seqüência de eventos. Assim, não é a simples presença do apoio visual que provoca diferentes níveis de produção, mas a natureza da seqüência apresentada (seqüência de eventos vs. situação-problema).

A conclusão comum derivada desses estudos é que as crianças são sensíveis às situações de produção, de forma que a habilidade narrativa pode emergir em uma situação, porém não em outra. Entretanto, observa-se Psicologia: Reflexão e Crítica, 2000, 13(3), pp.337-350 resultados contrastantes a respeito de se produzir a partir de apoios visuais dificulta (e.g., Spinillo,1991; 1993; Spinillo \& Pinto, 1994) ou facilita a produção de histórias elaboradas (e.g., Cain, 1996; Cain \& Oakhill, 1996; Shapiro \& Hudson, 1997). Para responder a esta questão torna-se necessário analisar a natureza do apoio visual fornecido. Nos estudos de Spinillo, a seqüência de gravuras restringia-se a uma seqüência de ações desempenhada pelos personagens, justificando-se assim, a tendência das crianças em descrever as gravuras ao invés de produzir uma histórias. Nos estudos de Cain e de Shapiro e Hudson, as gravuras incluíam uma situação-problema que levava à produção de histórias estruturadas e organizadas. Esta análise oferece uma explicação para resultados tão contrastantes, evidenciando que não apenas as diferenças entre tarefas são aspectos importantes, mas, ainda, a natureza do material fornecido como estímulo a partir do qual a história vai ser produzida. A inclusão de uma situação-problema representada nas gravuras parece ser elemento essencial para a emergência de estruturas narrativas mais elaboradas. Seria a escrita de histórias também susceptível a variações experimentais e à natureza do apoio fornecido? Ou por se tratar de um texto escrito tais variações não ocorreriam?

\section{Produção Escrita}

Como mencionado, estudos que examinam o efeito de variações experimentais sobre a escrita de histórias são raros. Pontecorvo e Morani (1996) conduziram um estudo piloto de natureza exploratória com oito crianças de seis e sete anos. Os dados foram coletados longitudinalmente através de atividades desenvolvidas em sala de aula. O corpus de 15 histórias consistia em: (a) quatro reproduções de um conto de fadas feitas em díades; (b) seis histórias inventadas individualmente $\mathrm{e}$ ditadas para o examinador; (c) duas histórias orais inventadas por uma díade, a partir de uma gravura e ditadas para o examinador; (d) três histórias inventadas e escritas em díades, a partir de uma gravura e de tema fornecido. Diversos aspectos foram discutidos, porém apenas aqueles relativos ao nível da estrutura narrativa são aqui considerados. Notou-se que não havia grandes diferenças entre inventar e reescrever, pois as histórias em ambas as condições eram geralmente bem organizadas e articuladas, particularmente quando produzidas em díades. As discussões focalizavam a interação entre as díades, interação esta que, segundo as autoras, variava em função da idade, da familiaridade com a tarefa e com o parceiro. As interações eram mais freqüentes quando a história era inventada do que quando reproduzida. 
Apesar de seu valor heurístico, o estudo não esclarece o efeito das condições de produção sobre a escrita de histórias dado a variabilidade entre as situações e a pouca sistematização adotada no planejamento do estudo, tornando difícil comparações entre as condições de produção. Além do número reduzido de histórias (15 ao todo); as crianças (individualmente ou em díade) não eram colocadas nas mesmas condições de produção, o que impede uma análise do desempenho de uma mesma criança ao longo do tempo e ao longo das diversas situações de produção. Os dados, portanto, devem ser entendidos como uma discussão exploratória sobre o tema, sem que possam ser extraídas conclusões sobre as relações entre condições de produção e escrita de histórias.

Aspectos a Considerar sobre a Escrita de Histórias

Pelo exposto, sabe-se mais a respeito da produção oral do que sobre a produção escrita; principalmente em relação ao efeito das condições de produção sobre a qualidade narrativa do texto escrito. Pelo visto, continuam em aberto algumas questões: A qualidade narrativa da história escrita seria, como ocorre com a produção oral, influenciada pelas condições de produção? Havendo tal influência, seria o efeito dessas variações o mesmo para todas as crianças? Há evidências, pelo menos na produção oral, de que existem crianças que são mais influenciadas pelas situações de produção do que outras, dependendo do domínio que apresentam do esquema narrativo de histórias (Spinillo, 1991, 1993). Ocorreria o mesmo com a produção escrita? Assim, a presente investigação procurou examinar o efeito das condições de produção sobre a escrita de história. Um segundo objetivo foi investigar o papel desempenhado pelos anos de escolaridade após a alfabetização.

\section{Método}

\section{Participantes}

Oitenta crianças de sete a dez anos, de classe média de escolas particulares da cidade do Recife, igualmente divididas em quatro grupos em função da escolaridade: primeira série (média: sete anos e oito meses), Segund série (média: oito anos e quatro meses), terceira série (média: nove anos e sete meses) e quarta séries (média: dez anos e sete meses) do ensino fundamental. As crianças estavam nas séries apropriadas para suas idades, não havendo repetentes na amostra.

Procedimento e Planejamento Experimental

As variáveis independentes eram as séries e as condições de produção. Diferentemente da grande maioria dos estudos que adotam grupos diferentes de crianças produzindo em condições experimentais diferentes, o planejamento ora adotado examina as mesmas crianças produzindo histórias escritas em situações distintas. Este planejamento permite comparar sujeitos de grupos diferentes (séries), produzindo histórias nas mesmas condições experimentais, e comparar o mesmo sujeito produzindo histórias em condições diferentes. Essas duas direções de comparação são consideradas na análise dos resultados.

A aplicação foi coletiva em três das quatro sessões, seguindo uma ordem fixa de apresentação: Condição 1 (Produção Livre), Condição 2 (Oral/escrita), Condição 3 (Gravuras) e Condição 4 (Reprodução). A Condição 2 foi aplicada individualmente. Esta ordem teve por objetivo apresentar inicialmente produções mais espontâneas, em situações mais livres, e posteriormente produções mais direcionadas por um modelo ou apoio visual ou lingüístico (gravuras e história ouvida, respectivamente). O tema, o tamanho da história e o tempo para sua elaboração ficavam a critério dos participantes. A estes era dito que, concluído o texto, este deveria ser lido, e que poderiam ser feitas as modificações que desejassem durante ou após a escrita do mesmo.

Antes, porém, da aplicação dessas sessões, avaliou-se memória a curto prazo dos participantes ${ }^{4}$, através de um teste de memória verbal elaborado por Jorm, Share, Macclean e Matthews (1984). Apresentava-se doze sentenças, lidas uma por vez pelo experimentador. Após a leitura de cada sentença a criança era solicitada a repetir a frase exatamente como a ouviu. A pontuação neste teste foi atribuída em função do número de frases corretamente repetidas, sendo considerado erro qualquer alteração na ordem das palavras da sentença, inserção ou omissão de palavras e troca por palavras sinônimas. Segundo a análise descritiva multidimensional (análise fatorial do tipo Análise de Correspondências, técnica formalizada no programa ADDAD.ANCOR@), a memória não foi fator determinante do desempenho dos sujeitos neste estudo. Isto provavelmente ocorreu devido ao fato de que os textos eram produzidos por escrito, estando disponíveis para consulta quer durante o processo de escrita quer ao final da produção, o que provavelmente neutralizou um possível efeito da memória.

${ }^{4}$ A justificativa para a inclusão desta avaliação é que a memória a curto prazo é considerada fator que pode influenciar o desempenho na produção de textos orais. Embora o presente estudo examine a produção escrita (situação menos susceptível aos efeitos de variações de memória do que a produção oral em que o texto não está fisicamente disponível), acreditou-se ser relevante explorar o possível efeito deste fator. 


\section{As Condições de Produção}

Condição 1 (Produção Livre): produção escrita de uma história original.

Condição 2 (Oral/ escrita): produção oral de uma história original, pedindo-se em seguida que escrevesse a mesma história que acabara de produzir oralmente. O objetivo era oferecer à criança a possibilidade de planejar, organizar e estruturar melhor suas idéias antes de registrá-las por escrito.

Condição 3 (Seqüência de gravuras): produção escrita de uma história a partir de uma seqüência de quatro gravuras que sugeria o tema, a cena, os personagens, a meta, uma situação-problema e uma resolução.

Condição 4 (Reprodução): produção escrita a partir de uma história lida pelo examinador ${ }^{5}$, a qual se baseia no modelo das gramáticas de história (Stein \& Glenn, 1979) que considera como o principal componente de uma história a presença de um plano de ação definido por um protagonista com o objetivo de atingir uma meta ou de solucionar um problema central. A seqüência de gravuras na Condição 3 sugere este mesmo modelo.

\section{Análise das Produções}

O sistema de análise, inspirado nas gramáticas de história, se baseia na classificação original de Rego (1986), posteriormente adaptada e utilizada em outros estudos (Spinillo, 1993; Spinillo \& Pinto, 1994). As 320 histórias escritas foram classificadas por dois juizes independentes, cujo índice de concordância foi de 85\%. As categorias de análise refletem diferentes níveis de domínio da estrutura narrativa e das convenções lingüísticas típicas deste gênero de texto. Exemplos ${ }^{6}$, extraídos do corpus de histórias obtido, e uma breve descrição de cada categoria são apresentados a seguir:

Categoria I - não-histórias, consistindo em frases soltas, seqüência de ações, relatos pessoais, texto cartilhado, músicas e poesias. Exemplo:

"O barco

Meu primo veio de barco.

Ele vem trazendo um presente para mim.

Eu vui bus-ca no porto

- Primo que bom vê você

- Eu também acho vê você. "

Categoria II - introdução da cena e dos personagens, com a presença de marcadores lingüísticos convencionais de começo de história. Exemplo:

${ }^{5}$ A história apresentada foi anteriormente utilizada por Rego (1989). ${ }^{6}$ As produções são apresentadas fielmente, preservando-se a forma como foram escritas pelas crianças.

Psicologia: Reflexão e Crítica, 2000, 13(3), pp.337-350 "era uma vez duas criança

ajudante eles era muito

bom eles fazia mandado

para os zotos o zotos

gostava muito de eles"

Categoria III - semelhante à categoria anterior, apresentando ainda uma ação que sugere o esboço de uma situação-problema. Exemplo:

"Era uma vez um cacborro. Um cachorro que gostava muito de brincar um dia ele foi brincar com seus amigos de rodar o bambole e quando o bambole ai pulou para fora do bambole ele brincon muito ele ficon muito cancado foi descansar na sua casinha de madeira ele descanson e depois comeu ficou todo sujo e teve que tomar banho ele foi tomar banho mas não paresseu porque foram brincar de novo quando brincavam ficavam todos sujos mas não se sujou como ante so se sujou um pouquinho e foi para a su casinha dormirpara amanha brincar de novo."

Categoria IV - semelhante à categoria anterior, apresentando também tentativa(s) de resolução da situação-problema, estando o desfecho ausente. Exemplo: "Era uma vez um lindo cachorrinho que se perdeu na floresta e ele conbeceu um garoto muito triste por que perdeu sua fanilha e estava perdido na mata com os animais que vivião com ele dorminha no chãa sosinho com o cachoro um dia lindo como este estava dois homens casando quandu viro o garoto e perguntou o que ele estava fazendo ali sosinho na quele mato pergundou seu nome ele disse meo nome e Zesinho e meus pais morerão quando en sai para pegar frutos dise zesinho quando en estava vou tando escotei um barulho como se estivese espolindo ei cori para ver o que foi quando en jegui estava peguando fogo dai eu vim paraca."

Categoria V - o desfecho está presente, porém não é explicitado como a situação-problema foi resolvida. Exemplo:

"O peixinho

Era uma vez. um peixinho que muito teimoso que resolveu nadar até as margens do rio. Os amigos dele disserão que ele não devia ir porque lá era muito perigoso por causa de que tinha os pescadores. Ele não ouviu, não obedeceu niguém e resolveu ir sozinho. O pescador que estava no barco pescou ele com um azol. Ele queria ajudar os amiginhos mas ele não podia porque ele morreu."

Categoria VI - histórias completas com uma estrutura narrativa elaborada, onde o desfecho da trama é explicitado. Exemplo:

"João e José

João e José são dois amigos inseparáveis.

João foi chamar o José na casa dele para conversar. José veio conversar com João em frente a uma casa que tinha um pé de peiras.

Eles começaram a conversar quando José teve a idéia de roubar peiras na casa que se localizava na sua frente.João concordou com a idéia de roubarpeiras.

Os dois pularam a cerca da casa, subiram no pé de peiras. 
Totó apareceu. Totó é o cachorro daquela casa eles passaram muitos minutos naquela árvore.

Mas ou menos uns 45 minutos.João achou uma solução, e perguntou: José você tem um osso aí com você José respondeu tenho sim, para que você quer um osso.

Você ainda não entendeu.

Se nós jogarmos um osso para o cachorro, ele vai pegar o osso e nós descemos da árvore, pulamos a cerca e comemos as peiras.

Foi dito e feito. João jogou o osso, o cachorro foi pegar e eles desceram da árvore, pularam a cerca e comeram as peiras. "

\section{Resultados}

\section{Análise do Corpus de Histórias Produzido}

$O$ Efeito das Séries sobre a Produção Escrita

Após categorizadas, as histórias foram consideradas em função das séries (Tabela 1)

Tabela 1. Porcentagem ${ }^{1}$ de Histórias Escritas em cada Categoria por Série

\begin{tabular}{ccccc}
\hline Categorias & $1^{a}$ série & $2^{a}$ série & $3^{a}$ série & $4^{a}$ série \\
\hline I & 23 & 6 & 5 & 9 \\
II & 10 & 13 & 5 & 4 \\
III & 13 & 12 & 1 & 0 \\
IV & 10 & 18 & 11 & 6 \\
V & 21 & 11 & 16 & 10 \\
VI & 23 & 40 & 62 & 71 \\
\hline
\end{tabular}

${ }^{1}$ Porcentagem extraída do número total de histórias produzidas em cada série ( 80 histórias).

O Teste U de Mann-Whitney revelou diferenças significativas entre as séries (primeira $v s$. terceira: $p<0,0001$; primeira $v s$. quarta: $p<0,0001$; segunda $v s$. terceira: $p<0,05$ e segunda vs. quarta: $p<0,001)$. Estas diferenças apontam que as crianças da primeira e da segunda séries apresentavam desempenho semelhante entre si, produzindo histórias classificadas em todas as categorias. As histórias das crianças da terceira e quarta séries se concentravam na Categoria VI. Assim, parece que de um lado encontram-se as crianças da primeira e da segunda série e de outro, as da terceira e quarta séries, cujas histórias são raramente classificadas nas categorias mais elementares (Categorias I, II e III), caracterizando-se por produções mais elaboradas (Categorias V e VI). Os anos de escolaridade influenciam a escrita de histórias, porém, este efeito não se manifesta nos anos iniciais logo após a alfabetização.

\section{O Efeito da Situação sobre a Produção Escrita}

$\mathrm{O}$ efeito das condições em que as histórias foram produzidas sobre a qualidade narrativa das histórias é ilustrado na Tabela 2.

O Wilcoxon revelou diferenças significativas $(p<0,0001)$ entre algumas das condições de produção (C1 vs. C3; C1 vs. C4; C2 vs. C3; C2 vs. C4). Nota-se que as produções escritas não se diferenciam significativamente entre a $\mathrm{C} 1$ e a $\mathrm{C} 2$, nem tampouco entre a $\mathrm{C} 3$ e a $\mathrm{C} 4$. As diferenças ocorrem entre as condições que não oferecem um apoio ou um modelo $(\mathrm{C} 1+\mathrm{C} 2)$ e as condições que oferecem $(\mathrm{C} 3+\mathrm{C} 4)$. Este resultado indica que a C3 (gravuras) e a C4 (reprodução) favorecem a escrita de histórias elaboradas (Categoria VI); enquanto que na C1 (livre) e na C2 (oral/escrita) observa-se uma menor freqüência de histórias na Categoria VI. Isto ocorre porque na Condição 3 e na Condição 4 existem apoios que norteiam a produção da criança. Na Condição 3, o apoio oferecido é visual, em que a seqüência de gravuras sugere os personagens, a meta, o começo, o meio, a situação-problema e o desfecho. $\mathrm{Na}$ Condição 4, o apoio é lingüístico, em que o texto lido pelo examinador sugere um modelo de história que deverá ser reproduzido por escrito pela criança. $\mathrm{O}$ fato da seqüência de gravuras ser uma das condições que facilita a emergência de um esquema narrativo mais elaborado é explicado pelas discussões anteriormente desenvolvidas a respeito dos resultados contrastantes obtidos por Spinillo (1993; Spinillo \& Pinto, 1994) e por Cain (1996; Cain \& Oakhill, 1996) e Shapiro e Hudson (1997). No presente estudo, a seqüência de

Tabela 2. Porcentagem ${ }^{1}$ de Histórias Escritas por Categoria em Função das Condições

\begin{tabular}{ccccc}
\hline Categorias & $\begin{array}{c}\text { Condição } \\
\text { (Livre) }\end{array}$ & $\begin{array}{c}\text { Condição 2 } \\
\text { (Oral/escrita) }\end{array}$ & $\begin{array}{c}\text { Condição 3 } \\
\text { (Gravuras) }\end{array}$ & $\begin{array}{c}\text { Condição 4 } \\
\text { (Reprodução) }\end{array}$ \\
\hline I & 20 & 14 & 9 & 0 \\
II & 18 & 10 & 0 & 2 \\
III & 6 & 11 & 2 & 8 \\
IV & 8 & 24 & 6 & 8 \\
V & 13 & 10 & 27 & 10 \\
VI & 35 & 31 & 56 & 72 \\
\hline${ }^{1}$ Porcentagem extraída do número total de histórias produzidas em cada condição (80 histórias).
\end{tabular}


gravuras inclui uma situação-problema, o que provavelmente levou as crianças a produzirem histórias mais elaboradas.

Portanto, nota-se que de um lado estão as condições que não contribuem efetivamente para a emergência de uma estrutura narrativa mais elaborada (C1 - Produção Livre; e C2 - Oral/escrita), e de outro, aquelas que contribuem, favorecendo a construção de histórias completas e elaboradas (C3 - Gravuras e C4 Reprodução). O que há em comum entre as condições $\mathrm{C} 1$ e $\mathrm{C} 2$, e entre as condições $\mathrm{C} 3$ e C4? As duas primeiras condições se assemelham por serem produções livres, em que a criança cria livremente a história a ser escrita. Nas demais condições (C3 e C4), são fornecidos apoios ou modelos que, embora de natureza distinta (um é visual e o outro é lingüistico), auxiliam a escrita de histórias organizadas e elaboradas. Seria este padrão geral de resultados também observado em cada série separadamente?

\section{Relações entre Série e Condições de Produção}

O efeito das condições de produção sobre a qualidade da história escrita não é observado igualmente em todas as séries. O Teste de Friedman detectou uma interação significativa entre essas variáveis apenas em relação às crianças da primeira $(\phi<0,001)$ e da segunda série $(p<0,0001)$. Estas crianças escrevem histórias mais elaboradas quando a partir de um apoio (Condição 3 Gravura; e Condição 4 - Reprodução) do que quando na ausência deste (Condição 1 - Livre e Condição 2 Gravuras). Este padrão de resultados corresponde àquele obtido em relação à amostra como um todo (Tabela 2).

Entretanto, esta interação não ocorre nas séries mais adiantadas visto que, nestas séries as crianças produzem histórias estruturadas em todas as situações. Assim, o efeito da condição sobre a qualidade da produção depende do nível de escolaridade: crianças em séries iniciais tendem a produzir melhores histórias em condições em que há um apoio (visual ou lingüístico) que sirva de modelo; enquanto crianças em séries mais adiantadas produzem boas histórias em todas as condições. Este é um aspecto de desenvolvimento interessante que será discutido no final deste artigo, e relacionado a dados relativos à produção oral. Importante notar que, embora não significativa, existe uma tendência em produzir histórias na Categoria VI quando na Condição 4 (Reprodução). A importância da reprodução de histórias será tratada no final deste artigo.

\section{Análise da Performance Individual das Crianças}

Como mencionado, o planejamento experimental adotado permite, além da análise descrita até então, examinar cada criança nas diferentes situações de produção. A exemplo de Spinillo (1991, 1993), procedeuse uma análise da performance individual, identificando-se três níveis quanto ao desenvolvimento de habilidades narrativas.

Nivel 1: crianças que produzem histórias elementares (Categorias I e II) e em categorias intermediárias (Categoria III e IV) Em todas as condições as crianças produzem textos que não correspondem a histórias (categoria I), produzem apenas o começo (Categoria II), ou histórias incompletas, em que o desfecho está ausente (Categoria III e IV). Em nenhuma das situações as crianças deste nível produzem histórias completas com uma estrutura narrativa elaborada.

Nivel 2: crianças cujas produções escritas variam em função das situações. A variação ocorreu da seguinte forma: nas Condições 1 (Produção Livre) e Condição 2 (Contar/Escrever) as crianças produzem textos elementares; enquanto na Condição 3 (Gravuras) e na

Tabela 3. Porcentagem de Crianças em cada Nível por Série

\begin{tabular}{ccccc}
\hline Nível & $1^{\mathrm{a}}$ série & $2^{\mathrm{a}}$ série & $3^{\mathrm{a}}$ série & $4^{\mathrm{a}}$ série \\
\hline 1 & 25 & 10 & 0 & 0 \\
2 & 45 & 60 & 15 & 25 \\
3 & 30 & 30 & 85 & 75 \\
\hline
\end{tabular}

Condição 4 (Reprodução) produzem histórias completas com uma estrutura narrativa elaborada (Categorias V e VI). Essas crianças são mais sensíveis às variações experimentais do que aquelas agrupadas nos outros dois níveis. Esta variação decorre da presença de apoios (visual ou verbal) que auxiliam a escrita de histórias.

Nivel 3: crianças que produzem histórias bem elaboradas (Categorias V e IV) em todas as condições, demonstrando um domínio do esquema narrativo que emerge em todas as situações de produção.

Como mostra a Tabela 3, as crianças das séries iniciais encontram-se em níveis de desenvolvimento bastante semelhantes, o mesmo ocorrendo com as séries mais adiantadas. A diferença reside entre as duas séries iniciais e as duas séries mais adiantadas.

O Qui-quadrado confirma este resultado $(p<0,01)$. Nota-se que as crianças da primeira e da segunda séries não se diferenciam, pois se concentram no Nível 2, apresentando um mesmo percentual no Nível 3 (30\%). Por sua vez, a maioria das crianças da terceira e da quarta 
séries encontra-se no Nível 3 (produções elaboradas em todas as condições), estando ausentes crianças classificadas no Nível 1 (produções elementares em todas as condições).

\section{Conclusões e Comentários Finais}

As discussões acerca dos resultados deste estudo referem-se aos aspectos que influenciam a escrita de histórias por crianças: os anos de escolaridade, as situações de produção, bem como a interação entre esses fatores.

\section{Os Anos de Escolaridade}

Os anos escolares após a alfabetização contribuem para o desenvolvimento da escrita de histórias. Isto indica que mesmo após a alfabetização existe uma progressão, um caminho a ser percorrido para a aquisição de um esquema narrativo mais elaborado que se manifeste na escrita de textos. Esta aquisição não é, por assim dizer "nivelada" a partir da aprendizagem da leitura e da escrita. Ao que parece, o domínio do sistema de escrita não garante o domínio de uma habilidade narrativa escrita Esta habilidade parece progredir de forma mais acentuada na terceira e na quarta série do ensino fundamental, séries estas em que os textos, de modo geral, estão mais presentes na vida escolar das crianças em todas as áreas do conhecimento. Este contato mais intenso com textos pode contribuir para o desenvolvimento de um esquema narrativo mais elaborado.

As Situações de Produção e a Natureza do Tipo de Apoio Fornecido

Além da escolaridade, a situação de produção é também fator importante na escrita de histórias elaboradas. Semelhante ao que ocorre com a produção oral, a escrita também é influenciada pela situação de produção: as histórias com uma estrutura e organização lingüísticas mais sofisticadas foram aquelas produzidas nas situações em que eram fornecidos apoios (visual ou verbal) que auxiliavam na escrita de histórias.

Entretanto, a natureza dos tipos de apoio fornecido é aspecto que merece ser discutido. Como mencionado na fundamentação teórica deste artigo, não é a mera presença de uma seqüência de gravuras que contribui para a emergência de histórias organizadas e com uma estrutura narrativa elaborada, mas o fato desta seqüência inclui uma situação-problema. No presente estudo, a seqüência de gravuras envolvia uma situação-problema a ser resolvida pelos personagens, levando à escrita de histórias elaboradas. Este resultado é semelhante àquele verificado por outros pesquisadores em relação à produção oral de histórias (Cain, 1996; Cain \& Oakhill, 1996; Shapiro \&
Hudson, 1997). Ao que parece, tanto a produção oral como a escrita são favorecidas por seqüências de gravuras que sugerem uma situação-problema. Não seria, portanto, qualquer seqüência que auxiliaria a produção de histórias, pois como discutido, há gravuras que não facilitam o aparecimento de estruturas narrativas mais elaboradas (como foi o caso da seqüência meramente temporal adotada por Spinillo \& Pinto, 1994).

Porém, não apenas o apoio visual favorece a escrita de histórias bem estruturadas, o apoio lingüístico (história lida para a criança) aparece também como recurso importante. $\mathrm{O}$ que o texto-modelo apresentado na situação de reprodução oferece para a construção de uma boa história? Nas reproduções das crianças nota-se que elas não apenas reproduzem o tema, a cena, os personagens e suas ações, mas, sobretudo, as características textuais da história ouvida. $\mathrm{Na}$ realidade, a criança reproduz o modelo lingüistico que lhe é apresentado, "transportando-o" para a história que escreve. Isto também é observado quando se analisa, por exemplo, as produções de crianças que, expostas freqüentemente a textos no contexto familiar (ver estudo de caso de Rego, 1985), são capazes de incluir em suas produções orais o estilo e organização lingüística das histórias lidas pelos adultos. Ao reproduzir a criança reproduz não apenas o conteúdo, mas também a forma lingüística do texto apresentado. Este dado reforça a idéia de que o contato com textos (seja lendo por si mesmo ou ouvindo a leitura de textos por parte de adultos) é fundamental na aquisição de um esquema narrativo.

Apesar de reconhecer-se que um modelo fornecido (visual ou lingüístico) facilita a escrita de histórias, é necessário considerar que uma habilidade narrativa bem desenvolvida deve prescindir de apoios externos. Um exemplo disto é o desempenho de crianças que neste estudo eram capazes de escrever boas histórias em todas as situações apresentadas. É possível que para estas crianças, que dominam um esquema narrativo, o modelo de uma boa história esteja incorporado, internalizado, não necessitando de estímulos externos para sua emergência. Assim, o nível de influência da situação de produção sobre a qualidade da história varia em função do domínio de um esquema narrativo.

O Dominio de um Esquema Narrativo de Histórias e as Situações de Produção

O efeito da situação sobre a produção escrita parece não ser o mesmo para todas as crianças. Há aquelas que são menos sensíveis a variações na situação do que outras. Como indicam os resultados, o efeito dessas variações é 
pouco expressivo em crianças que não dominam a escrita de histórias (Nível 1: histórias elementares ou não-histórias), e sobre crianças que mostram um domínio efetivo deste gênero narrativo (Nível 3: histórias bem elaboradas). Este efeito é acentuado entre crianças em um nível intermediário (Nível 2: a qualidade narrativa das histórias variava em função da presença ou ausência de um apoio). Estes níveis expressam uma progressão, em que os anos de escolaridade têm a sua contribuição. Este desenvolvimento parece ser mais evidente após alguns anos de escolaridade, e não desde o início.

De modo geral, resguardando-se as devidas diferenças entre linguagem oral e linguagem escrita, os resultados deste estudo indicam que o desenvolvimento da habilidade narrativa de histórias parece se manifestar de forma bastante semelhante na produção oral e na produção escrita.

O Desenvolvimento da Escrita de Histórias no Contexto Escolar Seria possível desenvolver desde cedo, no contexto escolar, habilidades narrativas? Uma possibilidade é incluir desde a pré-escola um trabalho sistemático com textos. Observando salas de pré-escola e de alfabetização, nota-se que atividades com histórias se restringem, basicamente, a levar as crianças a produzir histórias, atividades estas muitas vezes realizadas a partir de uma única gravura ou de uma seqüência de gravuras que se caracteriza por ações temporalmente representadas. $\mathrm{Na}$ realidade, a natureza das gravuras deveria ser considerada pelo professor como um elemento importante na produção, bem mais do que algo que sugere um tema sobre o qual dissertar. As gravuras deveriam incluir uma situação-problema, metas a serem alcançadas e obstáculos a serem superados.

A reprodução de histórias orais (ver Rego, 1988) e a reescrita de histórias (ver Teberosky, 1995) poderiam ser conduzidas em sala de aula. Através de suas reproduções as crianças estariam reproduzindo não apenas o conteúdo do texto, mas sua estrutura. Note-se que a reescrita de textos, tradicionalmente realizada em sala de aula com o propósito de ensinar ortografia, regras gramaticais, pontuação etc., pode ser redimensionada no sentido de ser uma forma, dentre outras, de apresentar um modelo de texto à criança.

Teberosky (1995), compartilha esta linha de argumentação, afirmando que conhecer modelos convencionais de textos é essencial para o aprendizado da escrita e que este conhecimento pode ser gerado através da reescrita de textos, em que a imitação que ocorre na atividade de reescrever um texto-modelo "... implica um procedimento de adesão à forma em que a informação do modelo está codificada. Tal adesão traz consigo o respeito à organização e às escritas textuais e genéricas do texto-modelo.“ (p. 100). Assim, a reescrita não pode ser compreendida como uma mera cópia, pois permite às crianças repetir as formas em que a informação do texto-modelo está codificada, tratando-se, assim, de uma adesão aos elementos textuais.

Como se efetua a transposição do texto-modelo para os textos reescritos? Que aspectos do texto escrito a criança seleciona, ignora ou modifica em seus próprios textos? Estas questões são consideradas por Teberosky (1995), e poderiam ser consideradas em uma análise adicional sobre parte do material coletado neste estudo: sobre a escrita da história que a própria criança acabara de oralmente produzir (Condição 2), e em relação à escrita de uma história ouvida (Condição 4). Isto é tema de uma futura investigação.

\section{Referências}

Berman, R. A. \& Slobin, D. I. (1994). Introduction. Em R. A. Berman \& D. I. Slobin (Orgs.), Relating events in narrative: A crosslinguistic developmental study (pp. 1-38). Hillsdale, NJ: Lawrence Erlbaum.

Buarque, L. L. Higino, Z M. Miranda, E. M., Dubeux, M. H. \& Pedrosa, I. (1992). Avaliação do desempenho da rede pública escolar do Estado de Pernambuco na área de linguagem (Número Especial). Estudos em Avaliação Educacional, 5

Castell, S., Luke, A. \& MacClennan, D. (1986). On defining literacy. Em S. de Castell, A Luke \& K. Egan (Orgs.), Literacy, societ), and schooling: A reader (pp. 3-14). Cambridge: Cambridge University Press.

Cain, K. (1996). Story knowledge and comprehension skill. Em C. Cornoldi \& J. Oakhill (Orgs.), Reading comprebension difficulties: Processes and intervention (pp. 167-192). Mahwah, NJ: Lawrence Erlbaum.

Cain, K. \& Oakhill, J. (1996). The nature of the relationship between comprehension skill and ability to tell a story. British Journal of Developmental Psychology, 14, 187-201.

Dowker, A. D. (1986). Language play in young cbildren. Tese de Doutorado não publicada, Institute of Education, University of London, Londres, Inglaterra.

Hudson, J. A. \& Shapiro, L. R. (1991). From knowing to telling: The development of children's scripts, stories, and personal narratives. Em A. McCabe \& C. Peterson (Orgs.), Developing narrative structure (pp. 89-136). Hillsdale, NJ: Lawrence Erlbaum.

Jorm, A., Share, D., MacClean, R. \& Matthews, R. (1984). Phonological confusability in short-term memory for sentences as a predictor of reading ability. British Journal of Psychology, 75, 393-400.

Lins e Silva, M. E. \& Spinillo, A. G. (1998). Uma análise comparativa da escrita de histórias pelos alunos de escolas públicas e particulares. Revista Brasileira de Estudos Pedagógicos, 79(193), 5-16.

MEC (1997). Parâmetros Curriculares Nacionais - Lingua Portuguesa. Secretaria de Educação Fundamental, Brasília, DF

Olson, D. R. (1997). On the relations between speech and writing. Em C Pontecorvo (Org.), Writing development: An interdisciplinary view (pp. 320). Philadelphia: John Benjamins.

Orsolini, M. \& Di Giacinto, P. (1996). Use of referential expressions in 4 year-old children's narratives: Invented versus recalled stories. Em C. Pontecorvo, M. Orsolini, B. Burge \& L. B. Resnick (Orgs.), Children's early text construction (pp. 67-82). Mahwah, NJ: Lawrence Erlbaum. 
Pontecorvo, C. (1997). Studying writing and writing acquisition today: A multidisciplinary view Em C. Pontecorvo (Org), Writing development: multidisciplinary view. Em C. Pontecorvo (Org.), Writing development-
An interdisciplinary view (pp. xv-xxxi). Philadelphia: John Beniamins.

Pontecorvo, C. \& Morani, R.M. (1996). Looking for stylistic features in children composing stories: Products and processes. Em C. Pontecorvo, M. Orsolini, B. Burge \& L. B. Resnick (Orgs.), Children's early text construction (pp. 229-258). Mahwah, NJ: Lawrence Erlbaum.

Pontecorvo, C. \& Orsolini, M. (1996). Writing and written language in children's development. Em C Pontecorvo, M. Orsolini, B. Bure \&

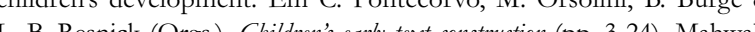
NJ: Lawrence Erlbaum. NJ: Lawrence Erlbaur.

Pontecorvo, C., Orsolini, M. \& Resnick, L. B. (1996). Introduction. Em C Pontecorvo, M. Orsolini, B. Burge \& L. B. Resnick (Orgs.), Children's early text construction (pp. ix-xvi). Mahwah, NJ: Lawrence Erlbaum.

Pontecorvo, C. \& Zucchermaglio, C. (1989). From oral to written language Pre-school children dictating stories. Journal of Reading Behaviour, 21 $109-126$

Rego, L. L. B. (1985). Descobrindo a língua escrita antes de aprender a ler: Algumas implicações pedagógicas. Revista Brasileira de Estudos Pedagógicos, 66,5-27.

Rego, L. L. B. (1986). A escrita de estórias por crianças: As implicações pedagógicas do uso de um registro lingüístico. Revista de Documentasãa de Estudos em Lingiüstica Térica e Aplicada, 2, 165-180.

Rego, L. L. B. (1988). Literatura infantil: Uma nova perspectiva da alfabetizacão na pré-escola. São Paulo: FTD.

Rego, L. L. B. (1989). A evolução da concepscão de bistória na crianca em três habilidades distintas: Memória, criacão e julgamento. Relatório técnico-científico não publicado. FINEP e Universidade Federal de Pernambuco, Recife, Pernambuco.
Shapiro, R. L \& Hudson, J. A (1997). Coherence and cohesion in children's stories. Em J. Costermans \& M. Fayol (Orgs.), Processing interclausal relationships: Studies in the production and comprebension of text (pp. 23-48). Mahwah, NJ: Lawrence Erlbaum.

Spinillo, A. G. (1991). O efeito da representação pictográfica na produção de narrativas. Psicologia: Teoria e Pesquisa,7, 311-326.

Spinillo, A. G. (1993). Era uma vez... e foram felizes para sempre. Temas em Psicologia. Desenvolvimento Cognitivo: Linguagem e Aprendivagem, 1, 67-87. Spinillo, A G. \& Pinto, G. (1994). Children's narratives under different conditions: A compantive study British Journal of Developmental Psycholge, 12,177-193.

Spinillo, A. G. \& Martins, R. A . (1997). Uma análise da producão de histórias coerentes por crianças. Psicologia: Reflexão e Crítica, 10, 219248.

Stein, N. L. (1988). The development of children's storytelling skill. Em M. B. Franklin \& S. Barten (Orgs.), Child language: $A$ book of readings (pp. 228-297). Oxford: Oxford University.

Stein, N. L. \& Glenn, C. G. (1979). An analysis of story comprehension in elementary school children. Em R. O. Freedle (Org.), New directions in discourse processing. Advances in discourse processes (Vol. 2, pp. 53-120). Norwood, NJ: Ablex

Teberosky, A. (1995). Compor textos. Em A. Teberosky \& L. Tolchinsky (Orgs.), Além da alfabetizaacão (pp. 85-116). São Paulo: Ática.

Sobre as autoras:

Maria Emília Lins e Silva é Professora do Centro de Educação da Universidade Federal de Pernambuco, Mestre em Psicologia pela Pós-Graduação em Psicologia da UFPE, atualmente realiza estudos de Doutorado no Departamento de Educação da Universidade Federal de Minas Gerais. Alina Galvão Spinillo é Professora Adjunta do Departamento de Psicologia da Universidade Federal de Pernambuco, atuando como Docente e Pesquisadora na Pós-Graduação em Psicologia desta universidade. Realizou Doutorado na University of Oxford e Pós-Doutorado na University of Sussex, ambos na Inglaterra. 
Anexo A

Seqüência de Gravuras Apresentada na Condição 3

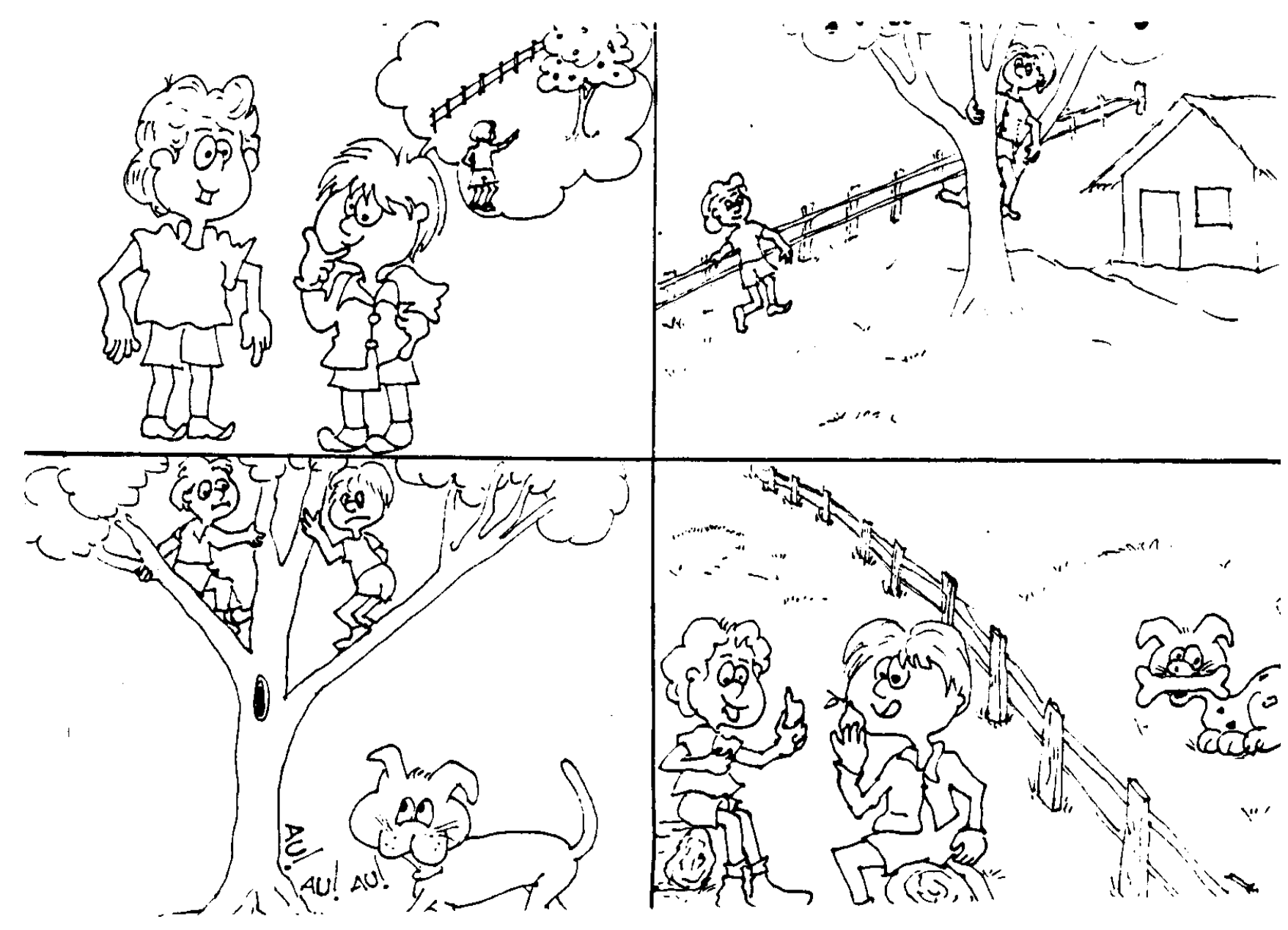




\section{História Lida pelo Examinador na Condição 4}

\section{O Peixe e a Minhoca}

Era uma vez um peixinho verde muito sapeca que se chamava Tonico. Ele morava em um grande e profundo lago que ficava próximo a uma enorme floresta. Todos os dias Tonico saia e passeava com seus amigos, mas nunca se aproximava das margens do lago.

Um dia Tonico resolveu viver uma grande aventura. Saiu nadando pelo lago na direção das margens. Logo adiante, Tonico encontrou um peixinho azul que se chamava Celeste. Tonico perguntou a Celeste se ele não queria acompanhá-lo e viver também uma grande aventura. Celeste se recusou porque ele era muito medroso e não gostava nada de aventuras. Mais adiante ele encontrou um peixinho amarelo que se chamava Leleco.

Leleco perguntou a Tonico para onde ele ia tão apressado. Tonico revelou-lhe a sua idéia de viver aventuras. Leleco aconselhou Tonico a voltar para casa, pois nesta época do ano era muito arriscado viver aventuras. Os pescadores estavam sempre por ali pescando peixes para vender. Tonico não deu ouvidos ao amigo e resolveu viver sozinho uma grande aventura. Afastou-se muito de onde seus companheiros estavam e nadou até bem perto das margens do lago. Foi então que ele viu uma grande e suculenta minhoca boiando na água. Tonico sabia muito bem o quanto eram deliciosas as minhocas, pois quando era menino sua mãe trazia sempre minhocas para ele comer, ela já tinha provado uma delas.

Tonico planejou, então, apanhar a minhoca para seu jantar. Assim, ele que era muito ágil, nadou rapidamente e conseguiu engolir a minhoca de um só golpe. Mas, de repente, antes que Tonico pudesse entender o que estava acontecendo, ele foi puxado violentamente para fora das águas e ficou pendurado em um anzol. Que triste sorte foi a de Tonico. Ele havia sido fisgado por um pescador. Enquanto o pobre Tonico debatia-se sem ar, ele lembrava da mãe e do conselho do amigo.

O pescador jogou Tonico no barco e logo lançou o anzol para fisgar outro peixe. Tonico, já quase morrendo, pensou: "Agora é tarde! Mas como seria bom se tivesse escutado o conselho de meu amigo. Bem que eu poderia ter sido mais cuidadoso. Ah! Se eu pudesse avisar os outros peixinhos." 